\title{
Allocation Equilibrium Analysis of Large-scale Instrument and Facilities Based on Triangular Fuzzy Numbers
}

\author{
Li Sun ${ }^{1}$ Yongbo $\mathrm{Lv}^{2}$ Fangpeng $\mathrm{Hu}^{3}$
}

School of Traffic \& transportation, Beijing Jiaotong University, Beijing 100044, China

\begin{abstract}
As a key index evaluating the development level of a region's technology, large-scale instrument and facilities, when being allocated, should be exerted to the utmost. This paper focuses on judging the allocation rationality of large scale instrument and facilities and building a simple model to support government's decision-making.
\end{abstract}

Keywords: Large-scale instrument and facilities; allocation; rationality; triangular fuzzy numbers

\section{Introduction}

Undoubtedly, large-scale instrument and facilities play a very important role in advocating the development of science and technology and almost every scientific research relies on large-scale instrument and facilities to testify the accuracy of the results. With the fast development of economy and technology, many regions demand more and more large-scale instrument and facilities. I $t$ has been an imminent problem to solve that government, as the institution allocating large-scale instrument and facilities, needs rigid and reasonable judging criteria to support decisionmaking when examining and endorsing investment on large-scale instrument and facilities. This paper provides a simple method for government to judge.

\section{Present allocation situation of large- scale instrument and facilities}

In 2010, average utilization ratio of large-scale instrument and facilities in China reached 70 percent, a relative low number; survey suggested that in some region it had reached more than 120 percent, but in some region it was less than 30 percent. The great gap implied the disequilibrium of allocation of largescale instrument and facilities in China. The present allocation situation in China can be divided in three conditions in terms of the overall quantity of largescale instruments and facilities in China: excessive allocation, proper allocation and deficient allocation. This paper centers on excessive allocation and deficient allocation for proper allocation is the ideal one.

\subsection{Reasons for irrational allocation of large-scale instrument and facilities}

Excessive allocation of large-scale instrument and facilities means the supplied quantity exceeds the needed, which features on low utilization ratio and low annual effective working hours.

There are four main reasons leading to excessive allocation. Firstly, after allocated, many large-scale instrument and facilities are idle, while, when needed, new ones will be bought by scientific research institutions. Secondly, many 
scientific research institutions often repeat the application for one facility. Thirdly, most of scientific research institutions would not like to share their resource, even keep secret. Fourthly, some institution has sufficient money to buy what they want. Overall, excessive allocation can be attributed to the management system.

Reasons for deficient allocation of largescale instrument and facilities

Deficient allocation of large-scale instrument and facilities means the supplied quantity was less than the needed. Proper scarcity leads to low utilization ratio, but would not influence usual scientific research. Abrupt scarcity would probably disarrange regular scientific research, which may further cause great potential technology loss, so abrupt scarcity is not permissive.

Main reason for deficient allocation is that those undeveloped regions are short of scientific projects for their inferior research capacity. So when these regions apply for allocation of large-scale instrument and facilities, often they are denied. According to the above reason, when allocating large-scale instrument and facilities, government should considerate the equilibrium to advocate the mutual improvement among different regions.

\subsection{Loss of irrational allocation of large-scale instrument and facilities}

Undoubtedly, excessive allocation of large-scale instrument and facilities will cause great economic loss. Firstly, largescale instrument and facilities are costly. We name facility as large-scale one when it is worth more than ten thousand yuan, so excessive allocation is a great waste. Secondly, excessive allocation means excessive management cost for largescale instrument and facilities need special management and maintenance. Thirdly, excessive allocation of large- scale instrument and facilities wastes land for their large volume.

Loss of deficient allocation of largescale instrument and facilities includes the real economic loss and the potential loss of technology development. Economic loss refers to existing facilities' overload operation. Short of facilities makes existing facilities operation exceed its optimum utilization ratio, which will accelerate its machine wear, add up maintenance and repair cost and shorten its lifespan.

It is called potential loss of technology development when some potential substantial discovery could not be found because of lacking corresponding facilities to support the research. The loss cannot be calculated, so we should avoid this situation when allocating large-scale instrument and facilities.

\section{Evaluation model for allocation equilibrium of large-scale instrument and facilities}

\subsection{Evaluation index system for allocation rationality of large- scale instrument and facilities}

We build the evaluation index system mainly through analyzing three aspects, namely, input level, utilization level and output level.

(1)Input level of large-scale instrument and facilities

Input level of large-scale instrument and facilities refers to the scale, structure, development, allocation, research of a region's large-scale instrument and facilities and those factors are most fundamental evaluation content. Input level of large-scale instrument and facilities mainly consists of original value of large-scale instrument and facilities, original value of newly added large-scale instrument and facilities in latest three years, proportion of instrument and 
facilities worthy over 2 million yuan and average original value of each researcher and developer.

(2)Utilization level of large-scale instrument and facilities

Utilization level refers to utilization condition of large-scale instrument and facilities and it mainly consists of utilization ratio, utilization ratio of newly deployed instrument and facilities in latest three years, utilization ratio of facilities worthy more than 2 million yuan, proportion of full loaded facilities, overall effectual working hours and proportion of regular operational facilities. Utilization level of large-scale instrument and facilities reflects the allocation index of large-scale instrument and facilities directly.

(3)Output level of large-scale instrument and facilities

Output level of large-scale instrument and facilities refers to a region's capacity of output after allocation and it is used to evaluate a region's scientific and technological strength. It mainly consists of quantity of patent applications, patent licenses, quantity of scientific paper published inland and quantity of scientific paper published abroad.

In sum, evaluation index system for allocation rationality of large-scale instrument and facilities is tabled as below:

Table1 evaluation index system for allocation rationality of large-scale instrument and facilities

\begin{tabular}{|c|c|}
\hline \multirow{4}{*}{$\begin{array}{l}\text { A1 INPUT } \\
\text { LEVEL }\end{array}$} & B1 original value \\
\hline & $\begin{array}{l}\text { B2 original value of newly added in } \\
\text { latest three years }\end{array}$ \\
\hline & $\begin{array}{l}\text { B3 proportion of facilities worthy } \\
\text { over } 2 \text { million yuan }\end{array}$ \\
\hline & $\begin{array}{l}\text { B4 average original value of each } \\
\text { R\&D }\end{array}$ \\
\hline \multirow{4}{*}{$\begin{array}{l}\text { A2 } \\
\text { UTILIZA } \\
\text { TION } \\
\text { LEVEL }\end{array}$} & B5 utilization ratio \\
\hline & $\begin{array}{l}\text { B6 utilization ratio of newly } \\
\text { deployed instrument and facilities in } \\
\text { latest three years }\end{array}$ \\
\hline & $\begin{array}{l}\text { B7 utilization ratio of facilities } \\
\text { worthy more than } 2 \text { million yuan }\end{array}$ \\
\hline & B8 proportion of full loaded facilities \\
\hline
\end{tabular}

\begin{tabular}{c|l}
\cline { 2 - 2 } & B9 overall effectual working hours \\
\cline { 2 - 2 } & $\begin{array}{l}\text { B10 proportion of regular operational } \\
\text { facilities }\end{array}$ \\
\hline \multirow{4}{*}{$\begin{array}{c}\text { A3 } \\
\text { OUTPUT }\end{array}$} & B11 quantity of patent applications \\
\cline { 2 - 2 } LEVEL & $\begin{array}{l}\text { B12 quantity of patent licenses } \\
\text { published inland }\end{array}$ \\
\cline { 2 - 2 } & $\begin{array}{l}\text { B14 quantity of scientific paper } \\
\text { published abroad }\end{array}$ \\
\hline
\end{tabular}

\subsection{Determination of comprehensive evaluation model based on triangular fuzzy numbers}

(1)Select of comprehensive evaluation model

Analytic Hierarchy Process (AHP), a method combining qualitative analysis and quantitative analysis, is an effective method to solve complicated systematic decision-making. While there are a lot of uncertainties and blurring, evaluation are quite different from the real because of evaluators' subjective judgment. So the weight of judgment matrix should be fuzzed and varies at a proper range to make the decision more precise. ${ }^{[1]}$ Index value in the evaluation index system of large-scale instrument and facilities can be quantified, but it involves fuzzy conception whether the value is proper for a region or not. So Zadeh advanced fuzzy set theory in 1965. Triangular fuzzy number $\quad a=\left(a_{l}, a_{m}, a_{u}\right) \quad$ where $0<a_{l} \# a_{m} \quad a_{u}$ and the lower limit and upper limit of $a$ are $a_{l}$ and $a_{u}$ respectively. Its characteristic function can be expressed as below:

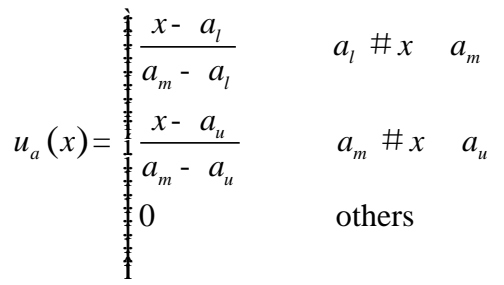

Combination of AHP and triangular fuzzy numbers is a practical method to evaluate object and it has been applied by many domestic scholars. ${ }^{[3],[4]}$ This paper 
uses the combination of AHP and triangular fuzzy numbers to evaluate the rationality of large-scale instrument and facilities in China.

(2)Determination of weight of the evaluation index system

Here we use AHP to determinate the weight of the evaluation index system. Invited specialists from field about management and application of largescale instrument and facilities compare the indexes in table 1 to one another two at a time and give a score out of 9,then get the weight of every index denoted by:

$$
w=\left[w_{1}, w_{2}, \ldots . w_{n}\right]
$$

(3)Comprehensive fuzzy evaluation based on triangular fuzzy numbers

According to the realistic condition and experience, specialists give a score in terms of triangular fuzzy numbers. When scoring, specialists rate the allocation with four levels: excessive, proper, deficient and severely deficient. The rate principle is as below:

Table 2 rate level

\begin{tabular}{|c|c|c|c|}
\hline $\begin{array}{c}\text { Excessive } \\
\text { allocation }\end{array}$ & $\begin{array}{c}\text { Proper } \\
\text { allocation }\end{array}$ & $\begin{array}{c}\text { Deficient } \\
\text { allocation }\end{array}$ & $\begin{array}{c}\text { Severely } \\
\text { deficiency }\end{array}$ \\
\hline$\geq 120$ & $(120,80]$ & $(80,50]$ & $<50$ \\
\hline
\end{tabular}

Assuming there are $\mathrm{E}$ specialists scoring, denoted as $E=\left[e_{1}, e_{2} \ldots e_{t}\right]$ and $n$ evaluation index. The corresponding evaluation result is denoted as $\left[a_{i j}, b_{i j}, c_{i j}\right]$, where $a_{i j}$ is the most conservative evaluation , $b_{i j}$ is the most possible evaluation and $c_{i j}$ is the most optimistic evaluation. Accordingly, initial comprehensive evaluation matrix based on triangular fuzzy numbers is as below:

$$
R=\left[\begin{array}{cc}
\left(a_{11}, b_{11}, c_{11}\right),\left(a_{12}, b_{12}, c_{12}\right) \ldots\left(a_{1 n}, b_{1 n}, c_{1 n}\right) \\
\left(a_{21}, b_{21}, c_{21}\right),\left(a_{22}, b_{22}, c_{22}\right) \ldots\left(a_{2 n}, b_{2 n}, c_{2 n}\right) \\
\vdots & \vdots \\
\left(a_{t 1}, b_{t 1}, c_{t 1}\right),\left(a_{t 2}, b_{t 2}, c_{t 2}\right) \ldots\left(a_{t n}, b_{t n}, c_{t n}\right)
\end{array}\right]
$$

Evaluation scored by specialists often varies with their personal experience and working environment, so weight of specialist's score, denoted as $E=\left[e_{1}, e_{2} \ldots e_{t}\right]$ Need to be determined. Then the weighted evaluation $\mathrm{R}^{*}$ can be expressed as below:

$$
\begin{aligned}
& R^{*}=\left[e_{i}, e_{2} \ldots e_{t}\right] \bullet\left[\begin{array}{c}
\left(a_{11}, b_{11}, c_{11}\right),\left(a_{12}, b_{12}, c_{12}\right) \ldots\left(a_{1 n}, b_{1 n}, c_{1 n}\right) \\
\left(a_{21}, b_{21}, c_{21}\right),\left(a_{22}, b_{22}, c_{22}\right) \ldots\left(a_{2 n}, b_{2 n}, c_{2 n}\right) \\
\vdots \\
\vdots \\
\left(a_{t 1}, b_{t 1}, c_{t 1}\right),\left(a_{t 2}, b_{t 2}, c_{t 2}\right) \ldots\left(a_{t n}, b_{t n}, c_{t n}\right)
\end{array}\right] \\
& =\left[\left(a_{1}, b_{1}, c_{1}\right),\left(a_{2}, b_{2}, c_{2}\right) \cdots\left(a_{n}, b_{n}, c_{n}\right)\right]
\end{aligned}
$$

Where $a, b$ and $c$ represent the most conservative evaluation, most possible evaluation and most optimistic evaluation respectively.

Comprehensive evaluation of an index can be calculated by synthesizing the weight determined by AHP and the evaluation determined by triangular fuzzy numbers and it can be expressed as below: $R_{C}=W \bullet R^{* T}=\left[w_{1}, w_{2}, \ldots w_{n}\right] \bullet\left[\left(a_{1}, b_{1}, c_{1}\right),\left(a_{2}, b_{2}, c_{2}\right) \ldots\left(a_{n}, b_{n}, c_{n}\right)\right]^{T}$

Where $\mathrm{a}, \mathrm{b}$ and $\mathrm{c}$ represent most conservative comprehensive fuzzy evaluation, most possible comprehensive fuzzy evaluation and most optimistic comprehensive fuzzy evaluation respectively.

Finally, the evaluation transferred by triangular fuzzy numbers, the allocation equilibrium index of large-scale instrument and facilities we want in this paper, can be calculated by availing the function $G=\frac{a+4 b+c}{6}{ }^{[6]}$.

\subsection{Judgment of the evaluation}

The ideal evaluation of equilibrium index obtained through the above method is 100 and it is deemed proper when the value is between 80 and 120 . If the value is over 120, it is deemed as excessive allocation of large-scale instrument and facilities in this region, between 50 and 80 as deficient allocation and less than 50 as severely deficient allocation. 


\section{Case analysis}

In terms of the difference of its applied fields, large-scale instrument and facilities can be separated into 15 categories: information technology, advanced technology, biology and medicine, aeronautics and astronautics, new material, advanced energy, modern agriculture, advanced manufacture, advanced environmental technology, marine science, safe and health, modern traffic, geological science and others. The allocation of large-scale instrument and facilities accords to the field and region, so does the evaluation. This paper evaluates large-scale instrument and facilities of biological medicine in Shandong province only with data in 2010 for the data reported are usually lagging.

\subsection{Fundamental data}

By the end of year 2010, the original value of large-scale instrument and facilities in Shandong province is 1824642000 yuan, which ranks $5^{\text {th }}$ nationally. Among all the large-scale instrument and facilities in Shandong province, biological medicine category's original value, 179207400 yuan, ranks $1^{\text {st }}$ nationally and its utilization ratio, 101.11 percent, ranks 4st nationally. Every index evaluated of Shandong province ranks top ten because of the rapid technology development. Specific data is tabled as below:

\begin{tabular}{|c|r|r|}
\hline \multicolumn{1}{|c|}{ Index } & \multicolumn{1}{c|}{ Value } & Rank \\
\hline B1 & 17920.74 & 1 \\
\hline B2 & 6392.26 & 2 \\
\hline B3 & 100.00 & 1 \\
\hline B4 & 1.08 & 5 \\
\hline B5 & 140.50 & 4 \\
\hline B6 & 101.11 & 3 \\
\hline B7 & 140.50 & 4 \\
\hline B8 & 58.82 & 1 \\
\hline B9 & 4028.53 & 3 \\
\hline
\end{tabular}

\begin{tabular}{|l|r|c|}
\hline B10 & 97 & 9 \\
\hline B11 & 19199 & 4 \\
\hline B12 & 12226 & 4 \\
\hline B13 & 11105 & 4 \\
\hline B14 & 885 & 10 \\
\hline
\end{tabular}

Among these indexes, quantities of patent application and patent license are calculated according to biological medicine facilities' proportion of all large-scale instrument and facilities for precise data cannot be got because of different statistical criteria. Also, classification of inland and abroad papers is different from that of large-scale instrument and facilities. So here quantity of papers about medical health is used to be that of biological medicine.

\subsection{Comprehensive fuzzy evaluation}

Determination of index weight

Specialists are invited to compare every two indexes in table 1to score and AHP is used to determinate weight of indexes every grade, then the result is as below:

$$
\begin{aligned}
& W_{A}=[0.24,0.53,0.23] \\
& W_{A 1}=[0.27,0.23,0.24,0.26] \\
& W_{A 2}=[0.21,0.19,0.15,0.17,0.13,0.15] \\
& W_{A 3}=[0.18,0.26,0.24,0.32]
\end{aligned}
$$

Comprehensive evaluation based on triangular fuzzy numbers

Taking A2, utilization level, for example, the evaluation matrix based on triangular fuzzy numbers and scored by three specialists is as below:

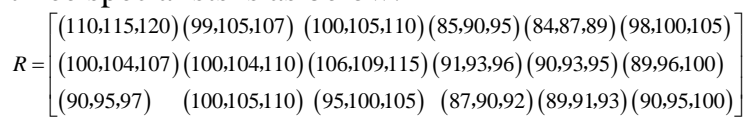

According to their working experience and backgrounds, weights of scores offered by three specialists are denoted as $E=[0.3,0.3,0.4] \quad$. Comprehensive evaluation matrix based on triangular fuzzy numbers is got by synthesizing their scores as below: 


$$
R_{A 2}^{*}=E \bullet R_{A 2}=\left[\begin{array}{l}
(99.0,103.7,106.9,) \\
(99.7,104.7,109.1) \\
(99.8,104.2,109.5) \\
(87.6,90.9,94.1) \\
(87.8,90.4,92.4) \\
(92.1,96.8,101.5)
\end{array}\right]^{T}
$$

After synthesized by weights, comprehensive evaluation is got as below:

$$
R_{C 2}=W_{A 2} \bullet R_{A 2}^{*}{ }^{T}=(94.824,99.025,102.837)
$$

Then the comprehensive evaluation score is calculated as below:

$$
G_{A 2}=\frac{a+4 b+c}{6}=\frac{94.824+4 \times 99.025+102.837}{6}=98.96
$$

Likely, the other two comprehensive evaluations are as below:

$R_{C 1}=(97.342,99.257,103.360) \quad R_{C 3}=(89.986,93.495,97.523)$

Comprehensive evaluation scores of $\mathrm{A} 1$ and $\mathrm{A} 3$ are as below:

$$
G_{A 1}=99.62, G_{A 3}=93.58
$$

Comprehensive fuzzy evaluation of allocation of large-scale biological medicine instrument and facilities in Shandong province is as below:

$$
R_{A}=W_{A} \bullet R_{C}{ }^{T}=(94.32,97.81,101.74)
$$

And the final evaluation result is as below:

$G=\frac{a+4 b+c}{6}=\frac{94.32+4 \times 97.81+101.74}{6}=97.88$

As the final evaluation result suggested, equilibrium index of allocation of largescale instrument and facilities in Shandong province is 97.88 , the input level 99.62, the utilization level 98.96 and the output level 93.58, all larger than 90 . So allocation of large-scale instrument and facilities in Shandong province is quite rational.

\section{Conclusion}

This paper precisely evaluates the allocation of large-scale instrument and facilities for regions by availing the combination of AHP with triangular fuzzy numbers and it provides a criterion for allocation decision-making. In the research process, we find out that many large-scale instrument and facilities are in poor administration. It is strongly suggested that government should establish normal administrative institution to avoid facilities idle, arrange professional staff to be in charge of the facility and appraise large-scale instrument and facilities after allocated.

\section{Project funding}

Project is supported by the national science and technology platform: a special center (2013DDJ1ZY06), Technology assessment and statistical special (2013SE-0603) and Beijing Jiaotong University basic scientific research fund (2012JBM070)

\section{References}

[1] Hongwei Zhao, Puqiao Feng. Fuzzy analytic hierarchy process in airport STBY power applications [J]. Journal of Xi'an Aero technical College, 2005, (01): 6-9.

[2] Fanyong Meng. Interval number, triangular fuzzy numbers and its judgment matrix theory [D]. Journal of Guangxi University, 2008.

[3] Shanshan Liu [D]. the study of evaluation methods of value engineering of Tianjin University based on triangular fuzzy number, 2008.

[4] Yuan, Jing Li, Based on the triangular fuzzy number of civil aviation enterprises "management" safety evaluation model of the [J]. China Safety Science Journal, 2008, (9)

[5] Xiao Yu, Li Hua. Improved [J]. judgment matrix of triangular fuzzy number and its application based on fuzzy system and mathematics, 2003, (2). 